\title{
Pengaruh Model Pembelajaran PBL Terhadap Hasil Belajar Matematika Pada Siswa SDN Sari 1 Kelas V Kecamatan Gajah Kabupaten Demak
}

\author{
Budi Setyani $^{1^{*}}$, Murtono ${ }^{1}$, Slamet Utomo ${ }^{1}$ \\ ${ }^{1}$ Magister Pendidikan Dasar Universitas Muria Kudus \\ *Penulis Korespondensi, Setyani Budi. Magister Pendidikan Dasar Universitas Muria Kudus. Indonesia \\ .Email: setyanibudi82@gmail.com
}

\begin{abstract}
ABSTRAK
Keberhasilan pencapaian hasil belajar sesuai nilai ketuntasan dalam proses belajar mengajar merupakan indikator bahwa siswa mampu menyerap ilmu yang didapat dengan baik. Untuk meningkatkan hasil belajar dituntut adanya sinergi antara kurikulum, guru, siswa, bahan ajar, media, fasilitas, dan sistem pembelajaran yang menjadikan hasil belajar dapat tercapai secara maksimal. Penelitian ini bertujuan untuk menemukan pengaruh penggunaan model pembelajaran Problem Based Learning terhadap hasil belajar siswa pada materi Jarak, Waktu, dan kecepatan kelas V SD Gugus Sultan Agung Kecamatan Gajah Kabupaten Demak. Penelitian ini menggunakan metode penelitian eksperimen dengan pendekatan kuantitatif dan tehnik penelitian melalui tes. Desain penelitian yang digunakan adalah pretest-postest control group design, dimana sebagai kelas eksperimen model pembelajaran PBL adalah SDN Sari 1 Kecamatan Gajah Kabupaten Demak. Hasil penelitian menggunakan model pembelajaran problem based leaning terhadap hasil belajar matematika, siswa mampu mencapai rata rata kelas sebesar 83 dan ketuntasan belajar 100\%. Berdasarkan penelitian, disimpulkan bahwa model pembelajaran PBL dapat meningkatkan hasil belajar siswa pada pelajaran matematika pada materi Jarak, Waktu, dan kecepatan kelas V SD Gugus Sultan Agung Kecamatan Gajah Kabupaten Demak, oleh sebab itu guru perlu meningkatkan kualitasnya agar dapat menciptakan pembelajaran yang kreatif dan menyenangkan, serta menggunakan model pembelajaran yang tepat agar hasil belajar siswa meningkat.
\end{abstract}

Kata Kunci: Pengaruh, Model PBL, Hasil Belajar

\begin{abstract}
The success of achieving learning outcomes according to the value of completeness in the teaching and learning process is an indicator that students are able to absorb the knowledge gained properly. To improve learning outcomes, there is a demand for synergy between the curriculum, teachers, students, teaching materials, media, facilities, and learning systems that make learning outcomes achieved optimally. This study aims to find the effect of the use of Problem Based Learning learning models on student learning outcomes in the material Distance, Time, and speed of class V SD Agung Sultan Agung Cluster, District of Gajah Demak Regency. This study uses an experimental research method with a quantitative approach and research techniques through tests. The research design used was a pretest-posttest control group design, where as an experimental class PBL learning model was SDN Sari 1 Gajah Subdistrict, Demak Regency. The results of the study used a problem based leaning learning model towards mathematics learning outcomes, students were able to achieve an average grade of 83 and 100\% completeness. Based on the research, it was concluded that the PBL learning model can improve student learning outcomes in mathematics in Distance, Time, and speed class V material at Sultan Agung Elementary School, Gajah Subdistrict, Demak Regency, therefore teachers need to improve their quality in order to create creative and fun learning, and using appropriate learning models so that student learning outcomes improve.
\end{abstract}

Keywords: Influence, PBL Model, Learning Outcomes 


\section{PENDAHULUAN}

\section{Latar Belakang}

Pendidikan Sekolah Dasar merupakan pendidikan dasar yang memegang peran penting sebagai pembentuk kepribadian dan pola pikir anak. Di jenjang pendidikan Sekolah Dasar anak diajarkan berbagai ilmu sebagai pondasi anak untuk menjalani pendidikan di jenjang selanjutnya. Matematika adalah mata pelajaran pokok yang diajarkan pada pendidikan Sekolah Dasar. Matematika merupakan ilmu pengetahuan yang berperan penting dalam perkembangan ilmu pengetahuan dan teknologi, baik sebagai alat bantu dalam penerapan bidang ilmu yang lain maupun dalam pengembangan matematika itu sendiri. Dengan makna lain bahwa matematika mempunyai peranan yang sangat esensial terutama bagi sains dan teknologi.

Menurut Stephen Adam (2007) "Learning outcomes are statements of what a learner is expected to know, understand and/or be able to demonstrate at the end of a period of learning. They are usully defined in terms of a mixture of knowledge, skills, abilities, attitudes and understanding that an individual will attain as a result of his or her successfulengagement in a particular set of higher education experiences". Pendapat tersebut menyatakan bahwa hasil belajar tidak hanya tentang apa yang diketahui, dipahami, dan ditunjukkan pada akhir pembelajaran tetapi hasil belajar mencakup pengetahuan, keterampilan, kemampuan, sikap dan pemahaman yang akan dicapai seseorang sebagai hasil dari keterlibatannya yang berhasil dalam pembelajaran. Sudjana (2005: 22) sebelumnya juga berpendapat sama bahwa hasil belajar adalah kemampuan-kemampuan yang telah dimiliki oleh siswa setelah ia mengalami proses belajarnya.

Ada empat komponen penting yang berpengaruh dalam proses pembelajaran dan bagi keberhasilan siswa, yaitu bahan belajar, suasana belajar, media dan sumber belajar, serta guru sebagai subjek pembelajaran. Guru sebagai salah satu unsur dalam proses belajar mengajar memiliki peran yang penting yaitu sebagai pengajar yang melakukan transfer of knowledge dan sebagai pembimbing yang mendorong potensi siswa dalam belajar (Dani Firmansyah, 2015). Sedangkan kurikulum menjadi sebuah aturan dan tata tertib dalam penyelenggaraan pendidikan. Kurikulum yang dilaksanakan di Indonesia tidak terlepas dari tujuan pendidikan, kebutuhan pendidikan, kondisi pendidikan, dan perkembangan teknologi. Oleh sebab itu, kurikulum harus dikembangkan sesuai dengan tujuan utama pendidikan di Indonesia seperti yang tercantum di dalam UU Sistem Pendidikan Nasional nomer 20 tahun 2003.

Sekolah Dasar di Kecamatan Gajah Kabupaten Demak, secara serentak dari kelas I sampai dengan kelas VI melaksakan kurikulum 2013 mulai tahun pelajaran 2018/2019. Pembelajaran kurikulum 2013 menggunakan pembelajaran tematik terpadu kecuali pelajaran matematika. Mata pelajaran matematika dari dulu sampai saat ini masih dianggap pelajaran yang sulit dan sukar dipahami bagi peserta didik, sehingga setiap menghadapi pelajaran matematika anak-anak mejadi malas bahkan rasa takut menghinggapi benak mereka. Sehingga dalam menguasai konsep pelajaran yang disampaikan guru menjadi minim dan kurang matang. Ditambah lagi dalam pembelajaran, guru masih banyak menggunakan metode konvensional, dimana guru masih dominan dalam pembelajaran sehingga menjadi teacher centered learning. Pembelajarn berpusat pada guru menjadikan anak-anak kurang aktif bahkan ada yang asyik bermain sendiri. Hal tersebut, berimbas pada hasil belajar yang mereka peroleh menjadi rendah. Pada pelajaran matematika, hasil belajar siswa berdasarkan penilaian harian pada materi Jarak, Waktu, dan kecepatan masih rendah belum memenuhi kriteria ketuntasan minimal (KKM). 
Permasalah ini perlu segera diselesaikan dengan adanya perubahan proses pembelajaran yang lebih inovatif dan kooperatif, salah satunya dengan mengadakan penelitian eksperimen dan inovasi sistem pembelajaran. Usaha ini dilakukan untuk meningkatkan hasil belajar peserta didik. Untuk mengatasi permasalahn di atas, maka diterapkan model pembelajaran Problem Based Learning (PBL).

Model pembelajaran Problem Based Learning (PBL) adalah interaksi antara stimulus dengan respon, yang merupakan hubungan antara dua arah belajar dan lingkungan. Pembelajaran berdasarkan masalah merupakan model yang efektif untuk pengajaran proses berfikir tingkat tinggi. Model ini merupakan suatu pendekatan pembelajaran dimana siswa mengerjakan permasalahan yang autentik dengan maksud untuk menyusun pengetahuan mereka sendiri, mengembangkan inkuiri dan ketrampilan berfikir tingkat lebih tinggi, mengembangkan kemandirian, dan percaya diri (Murtono, 2017:213).

\section{Tujuan dan Manfaat Penelitian}

Menemukan pengaruh penggunaan model pembelajaran Problem Based Learning terhadap hasil belajar siswa pada materi Jarak, Waktu, dan kecepatan kelas V SD Gugus Sultan Agung Kecamatan Gajah Kabupaten Demak.

\section{Manfaat Penelitian}

1. Secara teoritis

Secara teoritis penelitian ini diharapkan dapat menghasilkan sintesis mengenai peningkatan hasil belajar siswa melalui model pembelajaran Problem Based Learning memberikan referensi bagi peneliti yang selanjutnya agar dalam penelitiannya lebih baik dan detail memperbaiki kekurangan dalam penelitian sekarang.

2. Secara Praktis

a. Bagi peneliti, mengetahui kondisi riel di lapangan tentang pembelajaran sehingga dapat menciptakan pembelajaran yang inovatif dan kreatif di Sekolah Dasar. b. Bagi siswa, melalui penerapan model pembelajaran Problem Based Learning pada pelajaran matematika materi operasi hitung pecahan, dapat meningkatkan kerja sama dan tanggung jawab dalam belajar kelompok serta dapat meningkatkan hasil belajar siswa dalam proses kegiatan belajar mengajar.

c. Bagi Guru, Penerapan model pembelajaran Problem Based Learning diharapkan dapat membantu guru dalam pembelajaran matematika sebagai sarana untuk meningkatkan ketrampilan guru dalam mengelola kelas dan mengembangkan pembelajaran secara optimal sehingga memperoleh hasil pembelajaran yang berkualitas sesuai yang diharapkan.

d. Bagi sekolah, Memberikan informasi kepada sekolah tentang model pembelajaran Problem Based Learning dapat memperbaiki kegiatan pembelajaran sehingga tercipta kualitas pendidikan yang bermutu dan dapat meningkatkan pemahaman serta kualitas hasil belajar siswa.

\section{METODE PENELITIAN}

\section{Lokasi Penelitian}

Penelitian ini dilakukan pada siswa Kelas V SD di Gugus Sultan Agung Kecamatan Gajah Kabupaten Demak dengan pengambilan 1 sampel SD untuk penelitian yaitu Kelas V, Kelas VA SD Negeri Sari 1, dan Kelas VB SD Negeri Sari 1.

\section{Metode yang digunakan :}

Metode penelitian yang digunakan dalam penelitian ini adalah penelitian eksperimen dengan pendekatan kuantitatif. Penelitian eksperimen di lakukan untuk mengetahui hubungan sebab-akibat antar variabel. Desain penelitian yang digunakan adalah pretest-postest control group design. Pretest postest control group design merupakan jenis penelitian eksprimen dengan jenis true 
eksperimental. Penelitian ini mengambil 2 kelas yang dijadikan subjek penelitan. Secara sistematis penelitian ini adalah:

1. Kelas eksperimen

Dalam pembelajaran kelas ini mengunakan model pembelajaran problem based learning.

2. Kelas kontrol

Dalam pembelajaran kelas ini mengunakan model pembelajaran konvensional.

\section{HASIL DAN PEMBAHASAN}

\section{Hasil Penelitian}

\section{Deskripsi Data Prasyarat Pretest}

Sebelum diadakan analisis data, terlebih dahulu diadakan uji prasyarat data yang terdiri dari uji normalitas sebaran dan uji homogenitas varians. Hasil dari uji prasyarat dalam penelitian ini adalah :

\section{Uji Normalitas}

\section{Analisis Uji Normalitas Pre Test}

Uji normalitas digunakan untuk membuktikan apakah variable yang digunakan mengunakan sebaran data berdistribusi normal atau tidak. Dalam penelitian ini dalam pretest menggunakan uji Lilliefors dengan alat bantu hitung menggunakan Microsoft Excel. Uji normalitas Lilliefors menggunakan kepercayaan 95\% dengan ketentuan normal jika Lo hitung < L tabel. Jika hasil Lo hitung > L tabel maka data distribusinya tidak normal.

Rumus uji normalitas yang digunakan adalah :

$$
\text { Lo =Nilai maksimal dari | } f(z)-s(z) \mid
$$

$$
\begin{aligned}
& \text { dengan } \\
& \mathrm{Z} \quad=\frac{x_{1}-\bar{x}}{S D} \\
& \mathrm{~F}(\mathrm{zi})=(\text { NORM.S.DIST(H3;TRUE) }) \\
& \mathrm{S}(\mathrm{zi})=\frac{\text { banyaknya angka pada data } k \mathrm{n} n}{\text { banyaknya angka pada seluruh data }}
\end{aligned}
$$

(Arikunto, 2018)
Keterangan :

$$
\begin{aligned}
& \mathrm{Z}=\text { transformasi dari angka } \\
& \text { berdistribusi normal } \\
& \mathrm{x}_{\mathrm{i}}=\text { nilai pada data } \\
& \overline{\mathrm{x}}=\text { rata rata } \\
& \mathrm{SD}=\text { Standar Deviasi }
\end{aligned}
$$

Kemudian mencari peluang

$\mathrm{F}(\mathrm{zi})=\mathrm{P}(\mathrm{zi})$ dengan menggunakan rumus excel

$\mathrm{F}(\mathrm{zi})=($ NORM.S.DIST $(\mathrm{H} 3 ;$ TRUE $))$

Keterangan :

$\mathrm{F}(\mathrm{zi})=$ Probabilitas komulatif normal

$\mathrm{S}(\mathrm{zi})=\frac{\text { banyaknya angka pada data } \mathrm{ke} n}{\text { banyaknya angka pada seluruh data }}$

$\mathrm{S}(\mathrm{zi})=$ Probabilitas komulatif empiris

Lo = nilai maksimum dari $|\mathrm{f}(\mathrm{z})-\mathrm{s}(\mathrm{z})|$

Langkah langkah penggunaan alat bantu Microsoft Excel yaitu :

1. Isilah data yang akan dianalisis (nilai pretest) ke dalam tabel

2. Menghitung rata rata data dengan rumus $=$ AVERAGE(number 1:number 2)

3. Menghitung standar devisiasi data dengan rumus $=\operatorname{STDEV}($ number 1 :number 2$)$

4. Hitunglah $\mathrm{z}, \mathrm{f}(\mathrm{z}), \mathrm{s}(\mathrm{z})$, dan $\mathrm{l} f(\mathrm{z})-\mathrm{s}(\mathrm{z}) \mathrm{l}$

$$
\mathrm{z}=\frac{x_{1}-\bar{x}}{S D}
$$

Dalam penghitungan menggunakan bantuan Microsoft excel diperoleh hasil nilai preetest nomer 1 Kelas Eksprimen sebagai berikut :

$$
\begin{aligned}
& \mathrm{x}_{\mathrm{i}}=\text { nilai pada data }=40 \\
& \overline{\mathrm{x}}=\text { rata rata } \quad=65,5 \\
& \mathrm{SD}=\text { Standar Deviasi }=13,563 \\
& \mathrm{Z}_{1}=\frac{x_{1}-\bar{x}}{S D} \\
& =\frac{40-65_{x} 5}{13_{x} 563} \\
& =-1,88 \\
& \mathrm{f}(\mathrm{z}) \quad=\text { NORMSDIST (data } 1) \\
& =\text { NORMSDIST }(-1,88) \\
& =0,03 \\
& \mathrm{~s}(\mathrm{z}) \quad=\text { komulatif frekuensi }= \\
& \text { banyaknya angka pada data ke } n \\
& \text { banyaknya angka pada selurwh data }
\end{aligned}
$$




$$
\begin{gathered}
=\frac{2}{20} \\
=0,100 \\
\begin{aligned}
|\mathrm{f}(\mathrm{z})-\mathrm{s}(\mathrm{z})| & =\text { nilai mutlak dari } \mathrm{f}(\mathrm{z})-\mathrm{s}(\mathrm{z}) \\
& =|0,03-0,100| \\
& =0,070
\end{aligned}
\end{gathered}
$$

5. Nilai liliefors adalah nilai maksimal dari

$$
|f(z)-s(z)|
$$

Nilai liliefors adalah nilai maksimal dari | $\mathrm{f}(\mathrm{z})$ - s(z) | dengan alat bantu excel adalah 0,170 untuk eksprimen.

6. Membandingkan nilai Lv dengan $\mathrm{L}$ tabel, jika $\mathrm{Lv}<\mathrm{Lt}$ maka data berdistribusi normal.

Berdasarkan penghitungan Uji Normalitas selanjutnya dengan menggunakan alat hitung microsoft office memperoleh hasil sebagai berikut :

Tabel 4.1

Hasil Uji Normalitas Kelas Awal Eksprimen

\begin{tabular}{|c|c|c|c|}
\hline Kelas & $\begin{array}{c}\text { Lo } \\
\text { hitung }\end{array}$ & L tabel & Kesimpulan \\
\hline $\begin{array}{c}\text { Kelas } \\
\text { Eksprimen }\end{array}$ & 0,170 & 0,198 & Normal \\
\hline
\end{tabular}

Berdasarkan data di atas, hasil yang diperoleh sebagai berikut :

Kelas Eksprimen

Lo $=0,170$ dan L tabel $=0,198$, Karena Lo $<\mathrm{L}$ tabel maka Ho diterima sehingga sampel berasal dari populasi yang berdistribusi normal.

Lo pada eksprimen menunjukkan lebih kecil daripada L tabel (Lo < L tabel). Dari data ini dapat disimpulkan bahwa Ho diterima, artinya pada uji normalitas awal kelas eksprimen berdistribusi secara normal.

\section{Uji Normalitas Akhir Postest}

Uji Normalitas Akhir digunakan untuk mengetahui tingkat distribusi nilai pada eksprimen. Sumber pengolahan data diambil dari nilai postest.

Rumus uji normalitas yang digunakan adalah :

\section{Lo = Nilai maksimal dari $|\mathbf{f}(\mathbf{z})-\mathbf{s}(\mathbf{z})|$}

dengan

$$
\begin{aligned}
& \mathrm{z} \quad=\frac{x_{1}-\bar{x}}{S D} \\
& \mathrm{~F}(\mathrm{zi})=(\text { NORM.S.DIST(H3; TRUE) }) \\
& \mathrm{S}(\mathrm{zi})=\frac{\text { banyaknya angka pada data ke } n}{\text { banyaknya angka pada seluruh data }}
\end{aligned}
$$

(Arikunto, 2018)

Keterangan :

$$
\begin{aligned}
\mathrm{Z} & =\begin{array}{l}
\text { transformasi dari angka } \\
\text { berdistribusi normal }
\end{array} \\
\mathrm{x}_{\mathrm{i}} & =\text { nilai pada data } \\
\overline{\mathrm{x}} & =\text { rata rata } \\
\mathrm{SD} & =\text { Standar Deviasi }
\end{aligned}
$$

Kemudian mencari peluang

$\mathrm{F}(\mathrm{zi})=\mathrm{P}(\mathrm{zi})$ dengan menggunakan rumus excel

$$
\mathrm{F}(\mathrm{zi})=(\text { NORM.S.DIST }(\mathrm{H} 3 ; \text { TRUE }))
$$

Keterangan :

$\mathrm{F}(\mathrm{zi})=$ Probabilitas komulatif normal

$$
\begin{aligned}
& \mathrm{S}(\mathrm{zi})=\frac{\text { banyaknya angka pada data } \mathrm{ke} n}{\text { banyaknya angka pada seluruh data }} \\
& \mathrm{S}(\mathrm{zi})=\text { Probabilitas komulatif empiris } \\
& \text { Lo } \quad \text { nilai maksimum dari }|\mathrm{f}(\mathrm{z})-\mathrm{s}(\mathrm{z})|
\end{aligned}
$$$$
\text { Dalam penghitungan uji normalitas }
$$
mengunakan bantuan Microwsoft Excel. Langkah langkah penggunaan alat bantu Microsoft excel yaitu :

1. Isilah data yang akan dianalisis (nilai postest) ke dalam tabel

2. Hitunglah rata rata data dengan rumus $=$ AVERAGE(number 1:number 2)

3. Hitunglah standar devisiasi data dengan rumus = STDEV(number 1:number2)

4. Hitunglah $\mathrm{z}, \mathrm{f}(\mathrm{z}), \mathrm{s}(\mathrm{z})$, dan $|\mathrm{f}(\mathrm{z})-\mathrm{s}(\mathrm{z})|$

Dalam penghitungan menggunakan bantuan Microsoft excel diperoleh hasil nilai postest nomer 1 Kelas Eksprimen sebagai berikut :

$$
\begin{array}{lll}
\mathrm{x}_{\mathrm{i}} & =\text { nilai pada data } & =70 \\
\overline{\mathrm{x}} & =\text { rata rata } & =83,000 \\
\mathrm{SD} & =\text { Standar Deviasi } & =9,787
\end{array}
$$




$$
\begin{aligned}
& \mathrm{Z}_{1}=\frac{x_{1}-\bar{x}}{S D} \\
& =\frac{70-83,00}{9,787} \\
& =-1,328 \\
& \mathrm{f}(\mathrm{z}) \quad=\text { NORMSDIST }(\text { data } 1) \\
& =\text { NORMSDIST }(-1,328) \\
& =0,092 \\
& \mathrm{~s}(\mathrm{z}) \quad=\text { komulatif frekuensi }= \\
& \text { banyaknya angka pada data ke } n \\
& \text { banyaknya angka pada seluruh data } \\
& =\frac{5}{20} \\
& =0,25 \\
& |\mathrm{f}(\mathrm{z})-\mathrm{s}(\mathrm{z})|=\text { nilai mutlak dari } \mathrm{f}(\mathrm{z})- \\
& \mathrm{s}(\mathrm{z}) \\
& =|0,092-0,25| \\
& =0,158
\end{aligned}
$$

5. Nilai liliefors adalah nilai maksimal dari

$$
|\mathrm{f}(\mathrm{z})-\mathrm{s}(\mathrm{z})|
$$

Nilai liliefors adalah nilai maksimal dari $|\mathrm{f}(\mathrm{z})-\mathrm{s}(\mathrm{z})|$. Berdasarkan dengan alat bantu excel Lo adalah 0,170 untuk eksprimen.

6. Membandingkan nilai Lv dengan $\mathrm{L}$ tabel, jika Lv < Lt maka data berdistribusi normal.

Berdasarkan penghitungan Uji Normalitas nilai postest selanjutnya dengan menggunakan alat hitung microsoft office memperoleh hasil sebagai berikut :

Tabel 4.2 Hasil Uji Normalitas Akhir

\begin{tabular}{lc}
\hline \multicolumn{1}{c}{ Data } & $\begin{array}{c}\text { Kelas Eksperimen } \\
\text { ( PBL) }\end{array}$ \\
\hline Standar Devisiasi & 9,787 \\
Rata Rata & 83,000 \\
Alfa & 0,050 \\
Lilifors & 0,886 \\
Lt (L tabel) & 0,198 \\
Lv (L hitung) & 0,170 \\
\hline Kesimpulan & Normal \\
\hline
\end{tabular}

Berdasarkan data di atas, pada eksprimen Lo (L hitung) sebesar 0,170, sedangkan nilai L tabel sebesar 0,198. Hasil Lo $<$ L tabel yaitu $0,170<0,198$ artinya kelas eksprimen yang mengunakan model pembelajaran problem based learning berdistribusi normal.

\section{Uji Homogenitas Eksprimen}

Uji homogenitas akhir digunakan untuk mengetahui kondisi pada eksprimen. Kondisi ideal yang diharapkan sama. Eksprimen menggunakan pembelajaran dengan model pembalajaran problem based learning. Sumber pengolahan uji homogenitas ini diambil dari nilai pretest dan postest dengan menggunakan bantuan penghitungan melalui Microsoft Excel.

Rumus untuk menghitung varians atau standar deviasi variable $\mathrm{x}$ dan $\mathrm{y}$ adalah :

$$
\begin{aligned}
\mathrm{S}_{\mathrm{x}}{ }^{2} & =\sqrt{\frac{n\left(\sum X^{2}-\left(\sum X\right)^{2}\right.}{n(n-1)}} \\
\mathrm{Sy}^{2} & =\sqrt{\frac{n\left(\sum Y^{2}-\left(\sum Y\right)^{2}\right.}{n(n-1)}}
\end{aligned}
$$

Untuk mencari $\mathrm{F}$ hitung dari varians $\mathrm{x}$ dan $\mathrm{y}$, menggunakan rumus :

$$
\mathrm{F}=\frac{s_{\text {besar }}}{s_{\text {kecil }}}
$$

$\mathrm{S}$ besar artinya variance dari kelompok dengan variance terbesar

$\mathrm{S}$ kecil artinya variance dari kelompok dengan variance terkecil

Jika variance mempunyai ukuran yang sama, maka untuk pembilang dan penyebut bebas dipilih.

Dari data eksprimen diperoleh :

$\mathrm{n}=20$

$$
\begin{aligned}
& \sum X^{2}=91.300 \\
& \sum X=1.330 \\
& \sum Y^{2}=143.000 \\
& \sum Y=1.680
\end{aligned}
$$

$$
\mathrm{S}_{\mathrm{x}}{ }^{2}=\sqrt{\frac{n\left(\sum X^{2}-\left(\sum X\right)^{2}\right.}{n(n-1)}}
$$


Dan alpha $=0,05$ memiliki nilai $\mathrm{f}$ tabel 2,17

Berdasarkan data di atas diperoleh $\mathrm{F}$ hitung sebesar 1,23 sedangkan $F$ tabel sebesar 2,17 . Hal ini berarti $F$ hitung $<F$ tabel yaitu 1,23 $<2,17$ artinya data keduanya dikatakan homogen.

\section{Uji Pengaruh Model Pembelajaran Problem Based Learning terhadap Hasil Belajar Matematika Kelas V}

Kelas eksprimen menggunakan pembelajaran model problem based learning. Eksprimen ini dilaksanakan pada kelas V SD Negeri Sari 1 Kecamatan Gajah. Siswa dalam eksprimen ini berjumlah 20 siswa.

Setelah dilaksanakan postest diperoleh sebaran nilai dari 10 soal pilihan ganda. Hasil sebaran ini diadakan analisis deskriptif yaitu analisis menggunakan metode statistik dengan tujuan memperoleh pola sejumlah penelitian, merangkumnya dan terus menyajikan informasi sesuai bentuk yang diinginkan.

\section{Daftar Distribusi Frekuensi}

Dari hasil postest diperoleh data sebagai berikut:

Tabel 4.3 Hasil Nilai Eksprimen Model Pembelajaran Problem Based Learning

\begin{tabular}{ccccc}
\hline No & Nilai & Tabulasi & Frekuensi & $\begin{array}{c}\text { Nilai x } \\
\text { Frekuensi }\end{array}$ \\
\hline 2 & 70 & IIIII & 5 & 350 \\
3 & 80 & IIIII I & 6 & 480 \\
4 & 90 & IIIII II & 7 & 630 \\
5 & 100 & II & 2 & 200 \\
\hline & Jumlah & & 20 & 1660
\end{tabular}

Dari penghitungan di atas diperoleh $\mathrm{f}$ hitung $=$ 1,23 dan dari grafik daftar distribusi $\mathrm{F}$ dengan $\mathrm{dk}$ pembilang $=20-1=19 \mathrm{dan} \mathrm{dk}$ penyebut $=\mathrm{n}$ $-1=20-1=19$. 


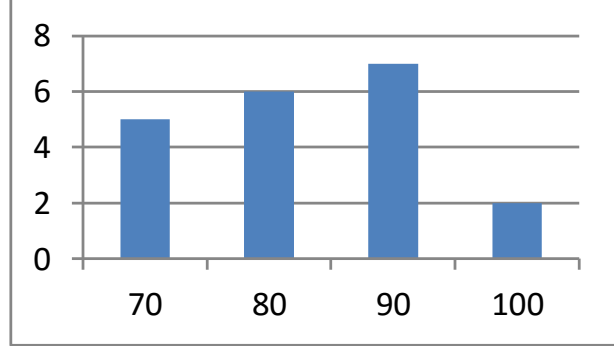

Gambar 4. 1 Diagram Nilai Eksprimen

Mean, Median, dan Modus

Dari analisis data postest Eksprimen :

$$
\begin{aligned}
\text { Mean } & =\frac{\text { jumlah selurwh data }}{\text { jumlah siswa yang mengikwti tes }}=\frac{1660}{20} \\
& =83
\end{aligned}
$$

Median $=80$

Modus atau nilai terbanyak $=90$

\section{Ketuntasan Belajar}

KKM muatan pelajaran matematika 70 , berarti siswa yang memperoleh nilai lebih atau minimal 70 sebanyak 20.

Hal ini berarti, ketuntasan belajar yang diperoleh sebanyak

$$
\begin{aligned}
& =\frac{\text { jumlah seluruh siswa yang tuntas }}{\text { jwmlah siswa yang mengikwti tes }} \times 100 \% \\
& =\frac{20}{20} \times 100 \%=100 \%
\end{aligned}
$$

\section{Kesimpulan Pengaruh Model Pembelajaran Problem Based Learning}

Berdasarkan hasil deskriptif nilai postest Eksprimen, disimpulkan bahwa hasil belajar model pembelajaran problem based learning berhasil sesuai harapan.

Hal ini membuktikan model pembelajaran problem based learning berpengaruh terhadap hasil belajar matematika tentang kompetensi dasar jarak, waktu, dan kecepatan kelas 5 . Pendukung pengaruh model pembelajaran problem based learning terhadap hasil belajar matematika, siswa mampu mencapai rata rata kelas sebesar 83 dan ketuntasan belajar 100\%.

\section{PEMBAHASAN}

\section{Pengaruh Model Pembelajaran Problem Based Learning Terhadap Hasil Belajar Matematika.}

\section{Pengertian Model Problem based Learning (PBL)}

Menurut Arends (2008: 41) bahwa pada dasarnya model PBL menyuguhkan berbagai situasi bermasalah yang autentik dan bermakna kepada siswa, yang dapat berfungsi sebagai sarana untuk melakukan investigasi dan penyeledikan. Sedangkan menurut Dutch (dalam Amir, 2009: 21) model PBL merupakan metode instruksional yang menantang siswa agar belajar untuk belajar, bekerja sama dalam kelompok untuk mencari solusi bagi masalah yang nyata masalah ini digunakan untuk meningkatkan rasa keingintahuan serta kemampuan analitis dan inisiatif atas materi pelajaran.

Model PBL memiliki 3 ciri utama yaitu: (1) pembelajaran berbasis masalah yaitu serangkaian aktivitas pembelajaran yang harus dilakukan siswa, (2) aktivitas pembelajaran diarahkan untuk menyelesaikan masalah yang menempatkan masalah sebagai kata kunci dalam proses pembelajaran, (3) pemecahan masalah dilakukan dengan menggunakan pendekatan berfikir ilmiah yaitu proses berfikir dengan menggunakan metode ilmiah (berfikir secara deduktif dan induktif yang dilakukan secara sistematis dan empiris) (Hamruni, 2009).

Penelitian Heri Mulyanto et al., (2017) menyatakan bahwa Model pembelajaran berbasis masalah menekankan pada proses pengajaran dan pembelajaran yang lebih luas, mengembangkan pengetahuan yang bermakna, keterampilan dan sikap yang terkait dengan pembelajaran kolaboratif, sehingga dapat membangun pengetahuan kooperatif, membantu siswa untuk membangun hubungan eksplisit antara sikap terhadap kerja sama dan mencapai hasil pembelajaran, mengidentifikasi ketrampilan kolaboratif khusus yang dibutuhkan 
siswa, dan diperoleh melalui kolaborasi kelompok. Pembelajaran pemecahan masalah menjadi sangat penting dalam melatih peserta didik untuk menjadi lebih terampil, berpengetahuan luas, serta memiliki kemampuan kognitif, afektif, dan psikomotorik (Rizky Vaira et al., 2017).

\section{Karakteristik dan Hakikat Masalah dalam Model PBL}

Model pembelajaran tentunya mempunyai karakteristik yang berbeda-beda. Adapun karakteristik model PBL adalah sebagai berikut:

1. Permasalan menjadi starting point / hal pertama dalam belajar

2. Permasalahan berasal dari dunia nyata yang tidak terstruktur

3. Permasalahan membutuhkan perspektif ganda

4. Permasalahan yang disajikan dapat menantang/mengukur kemampuan peserta didik.

5. Permanfaatan berbagai sumber yang beragam serta evaluasi sumber informasi.

Syntaks Pembelajaran Problem Based

Learning Trianto dalam Murtono (2015:222) sebagai berikut:

Tahap 1 (orientasi siswa pada masalah)

Tahap ini guru menjelaskan tujuan pembelajaran, menjelaskankan logistik yang dibutuhkan, mengajukan fenomena atau demonstrasi atau cerita untuk memuncukkan masalah memotivasi siswa terlibat pada aktivitas pemecahan masalah yang dipilih.

Tahap 2 (mengorganisasi siswa untuk belajar)

Tahap ini guru membantu siswa untuk mendefinisikan dan mengorganisasikan tugas belajar yang berhubungan dengan masalah tersebut.

Tahap 3 (membimbing penyelidikan individual maupun kelompok)

Tahap ini guru mendorong siswa untuk mengumpulkan informasi yang sesuai, melaksanakan eksperimen, untuk mendapatkan penjelasan dan pemecahan masalah.

Tahap 4 (mengembangkan dan menyajikan hasil karya)

Tahap ini guru membantu siswa merencanakan dan menyiapkan karya yang sesuai seperti laporan, video, dan model serta membantu siswa untuk berbagi tugas dengan sesama temannya.

Tahap 5 (menganalisis dan mengevaluasi proses pemecahan masalah)

Tahap ini guru membantu siswa untuk melakukan refleksi atau evaluasi terhadap penyelidikan mereka dan proses- proses yang mereka gunakan.

\section{Hasil Belajar}

Dalam proses pembelajaran terdapat tujuan pembelajaran yang diharapkan dapat dicapai setiap peserta didik setelah mengikuti pembelajaran. Tercapainya tujuan pembelajaran dapat dilihat dari hasil belajar peserta didik. Hasil belajar merupakan hasil perolehan dari proses belajar siswa sesuai dengan tujuan pengajaran (Purwanto, 2010:45).

Hasil belajar merupakan perubahan perilaku yang diperoleh pembelajar setelah mengalami aktivitas belajar. Menurut Krathwhol (2002) mengenai revisi Bloom, tipe hasil belajar dapat dibedakan menjadi 3, yaitu:

\section{Ranah Kognitif}

Ranah kognitif berkaitan dengan hasil berupa pengetahuan kemampuan dan kemahiran intelektual, yang mencakup kategori sebagai berikut:

a. Pengetahuan

Pengetahuan adalah sebagai perilaku mengingat atau mengenali informasi yang telah dipelajari sebelumnya. Pengetahuan merupakan tingkat hasil belajar paling rendah pada ranah kognitif

b. Pemahaman

Pemahaman adalah sebagai kemampuan memperoleh makna dari materi 
pembelajaran. Hasil belajar ini berada pada satu tahap di atas pengingatan materi sederhana.

c. Penerapan

Penerapan mengacu pada kemampuan menggunakan materi pembelajaran yang dipelajari dalam situasi baru dan konkrit. Hasil belajar ini memerlukan tingkat pemahaman yang lebih tinggi dari pada tingkat pemahaman sebelumnya.

d. Analisis

Analisis mengacu pada kemampuan memecahkan material ke dalam bagianbagian sehingga dapat dipahami struktur organisasinya. Hasil belajarnya mencerminkan tingkat intelektual lebih tinggi karena memerlukan pemahaman isi dan bentuk struktural materi pembelajaran yang dipelajari.

e. Sintesis

Sintesis mengacu pada kemampuan menggabungkan bagian-bagian dalam rangka membentuk struktur yang baru. Hasil belajar ini menekankan perilaku kreatif.

f. Penilaian

Penilaian mengacu pada membuat keputusan tentang nilai pembelajaran untuk tujuan tertentu. Hasil belajar ini paling tinggi di dalam ranah kognitif karena berisi unsur-unsur seluruh kategori tersebut dan ditambah dengan keputusan tentang nilai yang didasarkan pada kriteria yang telah ditetapkan secara jelas untuk mempermudah mengetahui tingkat kemampuan evaluasi seseorang.

\section{Ranah Afektif}

Ranah Afektif berhubungan dengan perasaan, sikap, minat, dan nilai. Kategori tujuan pembelajaran afektif adalah sebagai berikut:

a. Penerimaan
Penerimaan mengacu pada keinginan siswa untuk menghadirkan rangsangan. Hasil belajarnya bertentangan dengan kesadaran tentang adanya sesuatu sampai pada perhatian selektif yang menjadi bagian milik individu siswa. Penerimaan ini mencerminkan tingkat hasil belajar paling rendah di ranah afektif.

b. Penanggapan

Penanggapan mengacu pada partisipasi aktif pada diri siswa. Hasil belajar ini adalah penekanan pada kemahiran merespon, keinginan merespon.

c. Penilaian

Penilaian berkaitan dengan nilai yang melekat pada obyek, fenomena atau perilaku siswa yang didasarkan pada internalisasi seperangkat nilai tertentu, namun menunjukkan yang diungkapkan di dalam perilaku yang ditampakkan oleh siswa. Hasil belajar ini dikaitkan dengan perilaku yang konsisten dan cukup stabil di dalam membuat nilai.

d. Pengorganisasian

Pengorganisasian berkaitan dengan perangkaian nilai-nilai yang berbeda, memcahkan konflik-konflik antara nilai. Hasil belajar ini berkaitan dengan koseptualisasi nilai.

e. Pembentukan pola hidup

Pembentukan pola hidup mengacu pada individu siswa memiliki sistem nilai yang telah mengendalikan perilakunya dalam waktu cukup lama sehingga mampu mengembangkannya menjadi karakteristik gaya hidupnya.

3. Ranah Psikomotorik

Ranah Psikomotorik menunjukkan kemampuan fisik seperti ketrampilan motorik dan syaraf, manipulasi obyek, dan koordinasi syaraf. Jenis perilaku untuk ranah psikomotorik adalah sebagai berikut:

a. Persepsi 
Persiapan ini berkaitan dengan penggunaan organ penginderaan untuk memperoleh petunjuk yang memandu kegiatan motori.

b. Kesiapan

Kesiapan mengacu pada pengambilan tipe kegiatan tertentu yang mencakup pada kesiapan mental dan jasmani.

c. Gerakan terbimbing

Gerakan terbimbing berkaitan dengan tahap-tahap awal di dalam belajar ketrampilan kompleks.

d. Gerakan terbiasa

Gerakan terbiasa berkaitan dengan tindakan unjuk kerja. Hasil belajar ini berkaitan dengan ketrampilan untuk kerja dari berbagai tipe.

e. Gerakan kompleks

Gerakan kompleks berkaitan dengan kemahiran unjuk kerja dari tindakn motorik yang mencakup pola-pola gerakan yang kompleks. Hasil belajar ini mencakup kegiatan motorik yang sangat terkoordinasi.

f. Penyesuaian

Penyesuaian berkaiatan dengan ketrampilan yang dikembangkan sangat baik sehingga siswa dapat memodifikasi pola-pola gerakan sesuai dengan persyaratan baru.

g. Kreativitas.

Kreativitas mengacu pada menciptakan pola-pola gerakan baru untuk disesuaikan dengan situasi tertentu. Hasil belajar ini menekankan aktivitas yang didasarkan pada ketrampilan yang benar-benar telah dikembangkan.

Dari uraian di atas dapat disimpulkan bahwa hasil belajar meliputi ranah kognitif, afektif dan psikomotorik. Ranah kognitif merupakan pengetahuan dasar yang dimiliki seseorang dalam belajar. Ranah afektif merupakan sikap seseorang dalam belajar. Sedangkan ranah psikomotorik merupakan ketrampilan dalam mengerjakan sesuatu setelah seseorang mengalami ranah kognitif dan afektif. Apabila ketiga ranah tersebut dikuasai maka tujuan pembelajaran dapat tercapai.

Kunci pokok utama memperoleh ukuran dan data hasil belajar siswa adalah mengetahui garis besar indikator dikaitkan dengan jenis prestasi yang hendak diungkapkan atau diukur. Indikator hasil belajar menurut Benjamin S. Bloom dengan Taxsonomy of education objectives membagi tujuan pendidikan menjadi tiga ranah, yaitu kognitif, afektif, dan psikomotorik.

Brian R. Belland et al. (2009) dengan judul "Validity and Problem Based Learning Research: A Review of Instruments Used to Assess Learning Outcomes" penelitian ini meneliti bagaimana tiga hasil target PBL diukur dalam 33 studi empiris. Hasil menunjukkan bahwa beberapa studi termasuk (1) kerangka kerja teoritis untuk variabel yang dinilai dan konstruk, (2) rasional untuk bagaimana penilaian yang dipilih sesuai dengan konstruk yang diukur, (3) informasi lain yang diperlukan bagi pembaca untuk menilai validitas interpretasi penulis. Juga membahas implikasi penelitian masa depan.

Johannes Strobel dan Angela van Barneveld (2009) dalam penelitian When is $P B L$ More Effective? A Meta-synthesis of Metaanalyses Comparing PBL to Conventional Classroom, menghasilkan kesimpulan bahwa meta-analisis telah dilakukan yang memberikan sintesis efek PBL dibandingkan dengan bentuk pengajaran tradisional. Penelitian ini menggunakan pendekatan meta-sintesis kualitatif untuk membandingkan dan membedakan asumsi dan temuan penelitian meta-analitik tentang efektivitas PBL. Temuan menunjukkan bahwa PBL lebih unggul dalam hal retensi jangka panjang, pengembangan keterampilan dan kepuasan siswa dan guru, sementara pendekatan tradisional lebih efektif untuk retensi jangka pendek yang diukur dengan ujian dewan standar. 
Selcuk, Gamze Sezgin (2010) dalam penelitian The effects of problem-based learning on pre-service teachers' achievement, approaches and attitudes towards learning physics meneliti tentang evaluasi efek dari metode Problem Based Learning (PBL) pada prestasi siswa dalam dan pendekatan dan sikap terhadap kursus fisika pengantar. Hasil penelitian menunjukkan bahwa pembelajaran berbasis masalah metode tidak hanya mendorong pendekatan mendalam siswa untuk belajar, tetapi juga meningkatkan minat terhadap mata pelajaran fisika. Hasilnya juga memberi sinyal bahwa fisika berbasis PBL instruksi berdampak pada prestasi siswa dalam fisika secara positif. Kertas berakhir dengan beberapa implikasi untuk instruksi fisika.

Penelitian Bajaj Preeti et al. (2013) dengan judul "Problem Based Learning (PBL) An Effective Approach to Improve Learning Outcomes in Medical Teaching" Penelitian ini menyatakan bahwa Sebagai "Science of Medicine" semakin maju dari hari ke hari, kebutuhan akan pedagogik yang lebih baik dan teknik pembelajaran sangat penting. Pembelajaran berbasis masalah (PBL) adalah cara yang efektif untuk memberikan pendidikan medis dengan cara koheren, terintegrasi dan terfokus. Tujuan dan sasarannya untuk mengukur efektivitas Problem Based Learning.

Bekti Wulandari dan Hermawan Dwi surjono (2013) dengan judul "Pengaruh Problem Based Learning terhadap Hasil Belajar Ditinjau dari Motivasi Belajar PLC di SMK" Hasil penelitian menunjukkan bahwa: (1) Terdapat perbedaan hasil belajar antara siswa yang diajar dengan metode PBL dengan yang diajar metode demonstrasi, (2) Tidak terdapat pengaruh interaksi antara metode PBL dan demonstrasi dengan motivasi belajar terhadap hasil belajar, (3) Terdapat perbedaan hasil belajar antara siswa yang diajar dengan metode PBL dengan yang diajar dengan metode demonstrasi ditinjau dari motivasi tinggi dan rendah.
Muhammad Fachri Baharuddin Paloloang (2013) dalam penelitian "Penerapan Model Problem Based Learning untuk meningkatkan Hasil Belajar Siswa pada Materi Panjang Garis Singgung Persekutuan Dua Lingkaran di Kelas VIII SMP Negeri 19 Palu". Hasil penelitian menunjukkan bahwa melalui penerapan model PBL yang dapat meningkatkan hasil belajar siswa

Selanjutnya penelitian yang dilakukan Gd. Gunantara, Md. Suarjana, Pt. Nanci Riastini et al. (2014) dengan judul "Penerapan Model Pembelajaran Problem Based Learning untuk Meningkatkan Kemampuan Pemecahan Masalah Matematika Siswa Kelas V" Hasil penelitian menunjukkan bahwa penerapan model pembelajaran Problem Based Learning (PBL) dapat meningkatkan kemampuan pemecahan masalah yakni dari siklus I ke siklus II sebesar $16,42 \%$ dari kreteria sedang menjadi tinggi. Hal ini menunjukkan bahwa model pembelajaran PBL dapat meningkatkan kemampuan pemecahan masalah pada mata pelajaran matematika.

Penelitian Mark A. Albanese et al. (2014) dengan judul "Problem Based Learning: Outcomes Evidence From the Healt Professions" Penelitian ini menyatakan bahwa selama 30 tahun terakhir, pembelajaran berbasis masalah (PBL) telah menjadi kekuatan utama dalam pendidikan profesi kesehatan dan bahkan di dunia pendidikan. Hasil yang diidentifikasi dalam ulasan ini dijelaskan serta kekuatan bukti yang digunakan dalam dukungan mereka. Hasil tinjauan ini ditambah dengan hasil dari artikel terpilih yang menguraikan bagaimana PBL dapat menghasilkan hasil yang diidentifikasi.

Safrinal and Saminan (2015) dalam penelitian The Effect of Model Problem Based Learning (PBL) (Case Study at Class VIII MTsN Meureudu), Penelitian ini adalah penelitian deskriptif dengan menggunakan desain penelitian one group pretest dan posttest design. Data dikumpulkan dengan pretest dan posttest untuk mengetahui pengaruh penerapan model 
PBL dan lembar observasi untuk mengetahui kelayakan pembelajaran. Hasil penelitian menunjukkan bahwa mempengaruhi penerapan model PBL. Pengaruh tersebut dapat dilihat dari hasil pengujian hipotesis, nilainya secara signifikan lebih kecil dari $\alpha(0,05)$.

Sumartini, Tina Sri (2015) dalam penelitian Peningkatan Kemampuan Penalaran Matematis Siswa Melalui Pembelajaran Berbasis Masalah menyimpulkan Peningkatan kemampuan penalaran matematis siswa yang mendapatkan pembelajaran berbasis masalah lebih baik daripada siswa yang mendapatkan pembelajaran konvensional. Dari hasil penelitian diperoleh hasil belajar kelas eksprimen dengan jumlah responden 34 diperoleh hasil rata rata pretes 50,6 dan postes 72,8. Hal ini menunjukkan eksprimen Pengaruh Model Pembelajaran Problem Based Learning Dan Contextual Teaching and Learning Terhadap Hasil Belajar Matematika Pada Siswa SD Kelas V Gugus Sultan Agung lebih baik. Faktor penyebab hasil lebih baik, karena kualitas pembelajaran yang dihasilkan penelitian ini lebih baik dan menyempurnakan penelitian sebelumnya.

Dibandingkan dengan penelitian yang diadakan Utaminingsih, Sri dan kawan kawan (2015) dalam Penerapan Model Pembelajaran Berbasis Masalah (PBM) penelitian ini lebih baik. Hal ini dikarenakan keaktifan siswa dan keefektifan guru dalam mengajar lebih tampak dari penelitian sebelumnya. Hasil belajar semakin meningkat, hal ini dapat terlihat dari hasil tes akhir penelitian. Dengan menggunakan penelitian eksprimen model pembelajaran problem based learning terhadap hasil belajar matematika, ditunjukkan dengan siswa mampu mencapai rata rata kelas sebesar 83 dan ketuntasan belajar $100 \%$ sebanyak 20 siswa, sedangkan penelitian sebelumnya diperoleh hasil siswa mampu mencapai ketuntasan belajar $83,3 \%$.

Elaine H. J. Yew, Karen Goh (2016) Penelitian dengan judul "Problem Based
Learning: An Overview of its Process and Impact on Learning" Penelitian ini memberikan tinjauan umum tentang proses pembelajaran berbasis masalah (PBL) dan studi yang meneliti keefektifan PBL. Penelitian ini juga membahas Studi naturalistik dan empiris yang telah memeriksa proses PBL dan bagaimana berbagai komponennya mempengaruhi pembelajaran siswa. Hasil yang diperoleh menyimpulkan bahwa studi yang membandingkan efektivitas relatif PBL adalah umumnya konsisten dalam menunjukkan kemanjurannya yang unggul untuk retensi pengetahuan jangka panjang dan dalam penerapan pengetahuan. Namun proses PBL masih tidak konklusif untuk komponen PBL mana yang paling signifikan mempengaruhi pembelajaran siswa, meskipun studi kausal telah menunjukkan bahwa semua fase PBL diperlukan dalam mempengaruhi hasil belajar siswa.

Rahayu et al. (2016) dengan judul "Pengaruh Model Pembelajaran Problem Based Learning terhadap Berfikir Kritis dan Hasil Belajar Elastisitas Siswa Kelas XI SMA Negeri 7 Banda Aceh". Hasil penelitian ini menunjukkan bahwa terdapat pengaruh model PBL dalam meningkatkan hasil belajar, berfikir kritis dan berfikir kreatif siswa kelas XI pada mater Elastisitas.

Penelitian D Yuliati (2017), dengan judul Problem-Based Learning Model Used to Scientific Approach Based Worksheet for Physics to Develop senior High School Students Characters, Tujuan dari penelitian ini adalah untuk mengeksplorasi penerapan model Problem Based Learning (PBL) berbantuan dengan pendekatan ilmiah dan karakter Lembar kerja fisika terintegrasi (LKS) dan untuk menyelidiki peningkatan hasil belajar kognitif dan psikomotorik juga untuk mengetahui perkembangan karakter siswa. Lembar kerja dapat meningkatkan hasil belajar kognitif, psikomotorik siswa. Peningkatan dalam hasil belajar kognitif siswa yang telah belajar menggunakan lembar kerja lebih tinggi daripada siswa yang menerima pembelajaran tanpa 
lembar kerja. LKS juga dapat mengembangkan karakter siswa.

Rizky Vaira et al. (2017), dalam penelitian Contextual Learning And Learning Effectiveness Based On Problems With Learning Results Under The Neonatal Baby And Toddlers Care in Sari Mulia Midwifery Academy banjarmasin, Kegiatan belajar PBL 80\% sangat efektif dan kegiatan belajar CTL $60 \%$ efektif. Kesimpulannya, CTL dan PBL memiliki efektifitas dalam meningkatkan hasil belajar.

Penelitian yang dilakukan Peter Rillero, Malissa Tabault, Joi Merrit dan Margarita Jimenez-Silva (2018) dalam Bears in a boat: Science content and language development through a problem-based learning experience (2018) Problem Based Learning (PBL), masalah diajukan sebelum siswa belajar bagaimana menyelesaikannya. Bahasa dan PBL berpasangan dengan baik untuk lingkungan belajar yang efektif. Pembelajar Bahasa Inggris (ELL), kami mengembangkan pendekatan yang disebut Problem Based Enhanced Language Learning. Dalam artikel ini, diperoleh hasil belajar kontent sains adalah bahwa siswa akan dapat: (a) menggambarkan apa artinya tenggelam dan mengapung, (b) menjelaskan bahwa semakin banyak berat yang anda tambahkan ke kapal, semakin dalam akan mengambang.

Penelitian relevan yang lain adalah penelitian yang dilakukan Utami, Putri Rizky dkk (2019) yang berjudul Pengembangan Lembar Kerja Peserta Didik dengan Pembelajaran Berbasis Masalah Ditinjau dari Kemampuan Komunikasi dan Self Efficacy. Dari penelitiasn ini siswa mendapat skor terendah 20 dan tertinggi 95 dengan rata rata kelas 75,38 dan tingkat ketuntasan 76,9\%. Dibandingkan dengan penelitian ini, hasil postest kelas eksprimen penelitian eksprimen Pengaruh Model Pembelajaran PBL dan CTL Terhadap Hasil Belajar Siswa Pada Pelajaran Matematika Kelas V SD Gugus Sultan Agung Kecamatan Gajah Kabupaten Demak lebih baik.
Hal ini disebabkan karena siswa memperoleh pengalaman belajar yang lebih baik. Kualitas pembelajaran lebih optimal karena media, sarana, iklim yang digunakan lebih sesuai dengan karakter yang dibutuhkan anak.

Berdasarkan perbandingan dari penelitian sebelumnya penelitian eksprimen Pengaruh Model Pembelajaran PBL Terhadap Hasil Belajar Siswa Pada Pelajaran Matematika Kelas V SD Gugus Sultan Agung Kecamatan Gajah Kabupaten Demak lebih baik. Penelitian ini lebih baik karena penelitian ini merupakan penyempurnaan sebelumnya. Hal ini terlihat dari hasil postest yang diperoleh. Keberhasilan penelitian karena guru menerangkan dengan model yang tepat dan tumbuhnya keaktifan dari peserta didik dalam menerima pembelajaran. Pengaruh model pembelajaran problem based learning terhadap hasil belajar matematika, ditunjukkan dengan siswa mampu mencapai rata rata kelas sebesar 83 dan ketuntasan belajar $100 \%$ sebanyak 20 siswa.

\section{KESIMPULAN DAN SARAN}

\section{Simpulan}

Berdasarkan hasil penelitian dan pembahasan mengenai pengaruh model pembelajaran problem based leaning terhadap hasil belajar matematika yang telah dilaksanakan, maka dapat disimpulkan sebagai berikut:

Model pembelajaran problem based leaning berpengaruh terhadap hasil belajar matematika tentang kompetensi dasar jarak, waktu, dan kecepatan kelas 5. Pengaruh model pembelajaran problem based leaning terhadap hasil belajar matematika, ditunjukkan dengan siswa mampu mencapai rata rata kelas sebesar 83 dan ketuntasan belajar $100 \%$ sebanyak 20 siswa.

\section{Saran}


Berdasarkan temuan dan kesimpulan penelitian diatas, maka peneliti mengajukan beberapa saran sebagai berikut:

1. Kepala Sekolah perlu untuk memberi motivasi kepada guru untuk berinovasi dalam pembelajarannya.

2. Guru perlu meningkatkan kualitasnya agar dapat menciptakan pembelajaran yang kreatif dan menyenangkan.

3. Guru perlu menggunakan model pembelajaran yang tepat agar hasil belajar siswa meningkat.

4. Model pembelajaran problem based leaning sangat baik digunakan dalam pembelajaran, guru perlu menggunakan model tersebut dalam proses belajar.

\section{DAFTAR PUSTAKA}

Adam, Stephen. 2007. An Introduction to Learning Outcomes-A Consideration of the Nature, Function and Position of Learning Outcomes in the Creation of the European Higher Education Area. http://www.Introducing Bologna Objectives and Tools. Diunduh tanggal 12 Januari 2020.

Amir, M. Taufiq. 2009. Inovasi Pendidikan melalui Problem Based Learning. Bagaimana pendidik memberdayakan pemelajar di era pengetahuan. Jakarta: Kencana Predana Media Group

Arends, Richard, 2008. Belajar untuk mengajar. Edisi ke tujuh alih bahasa oleh Helly Prayitno dan Sri Mulyantani Prayitnodari judul Learning to Teach. Seven edition. Yogyakarta: Pustaka Belajar.

Arikunto, Suharsimi. 2013. Prosedur penilaian. Jakarta: PT. Rineka Cipta.

Bajaj Preeti, Ahuja Ashish, Gosavi Shriram. (2013). Problem Based Learning (PBL) An Effective Approach to Improve Learning Outcomes in Medical Teaching. Journal of Clinical and Diagnostic Research, Vol 7(12): 2896-2897.

Brian R. Belland, Brian F. French, Peggy A. Ertner. 2009. Validity and Problem Based Learning Research: A Review of Instruments Used to Assess Learning
Outcomes. The Interdisciplinary Journal of Problem-based Learninf, Vol 3, No1.

D Yuliati 2017. Problem-Based Learning Model

Used to Scientific Approach Based Worksheet for Physics to Develop senior High School Students Characters, Journal of Physics: Conference Series 824(2017)012009.

httpsiopscience.iop.orgarticle 10.10881742 -65968241012009pdf. Diunduh tanggal 19 April 2020

Dani Firmansyah. 2015. Pengaruh Strategi Pembelajaran dan Minat Belajar Terhadap Hasil Belajar Matematika. Jurnal Pendidikan UNSIKA, Vol 3, No 1, hlm 34-44. ISSN 2338-2996.

Depdiknas. 2003. Undang-undang RI No.20 tahun 2003. Tentang Sistem Pendidikan Nasional.

Elaine H.J Yew, Karen Goh. 2016. Problem Based Learning: An Overview of its Process and Impact on Learning. Health Professions Education 2, Hlm 75-79. www.sciencedirect.com. Diunduh tanggal 19 April 2020

Gd. Gunantara, Md. Suarjana, Pt. Nanci Riastini. 2014. Penerapan Model Pembelajaran Problem Based Learning untuk Meningkatkan Kemampuan Pemecahan Masalah Matematika Siswa Kelas V. Jurnal mimbar, vol 2 No 1,https://ejournal.undiksha.ac.id/index.ph $\mathrm{p} / \mathrm{JJPGSD} /$ article/download/2058/1795. Diunduh 4 September 2019.

Hamruni, 2009. Strategi Pembelajaran. Intan Madani: Yogyakarta.

Heri Mulyanto, Gunarhadi, Mintasih Indriayu. 2018. The Effect of Problem Based Learning Model on Student Mathematics Learning Outcomes Viewed from Critical Thingking Skills. International Jurnal of Educational Research Review, Vol 3, No 2, Hlm 37-45. http://iojet.org/index.php/IOJET/article/ view/392/253. Diunduh tanggal 19 April 2020.

http://www.scadindependent.org/2015/05/ peuradeun-745-1432662101.html.. Diunduh tanggal 19 April 2020.

Krathwohl, David R. 2002. "A revision of Bloom's Taxonomy: an overview Theory 
into practice" Jurnal College of Education The Ohio State University, 41(4): 212-264.

Mark A. Albanese, Laura Dast. 2014. Problem Based Learning: Outcomes Evidence From the Healt Professions. Journal on Excellence in Collage Teaching, 25(3\&4), 239-252.

Muhammad Fachri Baharuddin Paloloang. 2013. Penerapan Model Problem Based Learning untuk meningkatkan Hasil Belajar Siswa pada Materi Panjang Garis Singgung Persekutuan Dua Lingkaran di Kelas VIII SMP Negeri 19 Palu. Jurnal Elektronik Pendidikan Matematika Tadulako, Vol 2, No 1.

Murtono. 2017. Merencanakan dan Mengelola Model-Model Pembelajaran Inovatif (Student Center Learning). Ponorogo: WADE Group.

Peter Rillero, Malissa Tabault, Joi Merrit dan Margarita Jimenez-Silva. 2018. Bears in a boat: Science content and language development through a problem-based learning experience. Journal Science Activities Projects and Curriculum Ideas in STEM Classroom, vol 55, hlm1-2. https://www.tandfonline.com/doi/abs/10.1 080/00368121.2017.1406323. Diunduh 4 September 2019. Diunduh tanggal 12 Januari 2020.

Purwanto. 2010. Evaluasi Hasil Belajar. Yogyakarta: Pustaka Pelajar.

Rahayu. 2016. Pengaruh Model Pembelajaran Problem Based Learning terhadap Berfikir Kritis dan Hasil Belajar Elastisitas Siswa Kelas XI SMA Negeri 7 Banda Aceh. Jurnal Pendidikan, Vol 4, No 2, Hlm 105-116, https://media.neliti.com/media/publication s/122494-ID-pengaruh-model-problem-

based-learning-te.pdf. Diunduh 4 September 2019. Diunduh tanggal 12 Januari 2020.

Rizky Vaira, Andriana Palimbo, Susanti Suhartati. 2017. Contextual Learning And Learning Effectiveneess Based On Problems With Learning Results Under The Neonatal Baby And Toddlers Care in Sari Mulia Midwifery Academy Banjarmasin. 2nd Sari Mulia
International Conference on Health and Science. Advances in Healt Science Research Vol 6.

Safrinal and Saminan. 2015. The Effect of Model Problem Based Learning (PBL) (Case Study at Class VIII MTsN Meureudu), Jurnal Ilmiah PeuradeunInternational Multidisciplinary Journal Artc. OAJI ID: 745-1432662101

Selcuk, Gamze Sezgin (2010). The effects of problem-based learning on pre-service teachers' achievement, approaches and attitudes towards learning physics. international Journal of the Physical Sciences Vol. 5(6), pp. 711-723, June 2010

https://pdfs.semanticscholar.org/dba6/41e 9e71f401bea471a5cca87 2b95a5748921.pdf.

Strobel, Johannes Angela van Barneveld. 2009. When is PBL More Effective? A Metasynthesis of Meta-analyses Comparing $P B L$ to Conventional Classroom. Advances in Health Science Research, volume 6. 2nd Sari Mulia International Conference on Health and Sciences (SMICHS 2017).

Sudjana, N. (2005). Penilaian Hasil Proses Belajar Mengajar. Bandung: PT. Remaja Rosdakarya.

Sumartini, Tina Sri (2015). Peningkatan Kemampuan Penalaran Matematis Siswa Melalui Pembelajaran Berbasis Masalah. Jurnal Pendidikan Matematika Volume 5, Nomor 1, April 2015 hal. 1-10. https://journal.institutpendidikan.ac.id/ind ex.php/mosharafa/article/view/mv4n1_1/2 44.

Utami, Putri Rizky dkk (2019). Pengembangan Lembar Kerja Peserta Didik Dengan Pembelajaran Berbasis Masalah Ditinjau Dari Kemampuan Komunikasi dan Self Efficacy JPPM (Jurnal Penelitian dan Pembelajaran Matematika) hal 300 - 315 http://jurnal.untirta.ac.id/index.php/JPPM/ article/view/6221/pdf 7 .

Utaminingsih Sri, dkk (2015) Penerapan Model Pembelajaran Berbasis Masalah (PBM) untuk Meningkatkan Hasil Belajar IPA Siswa di Kelas V SD Negeri Pasuruhan Pati. Refleksi Edukatika: Jurnal Ilmiah Kependidikan http://jurnal.umk.ac.id/index.php/RE/ 
article/view/451 hlm 1-7. Diunduh tanggal 15 September 2018.

Wulandari, Bekti dan Hermawan Dwi surjono. 2013. Pengaruh Problem Based Learning terhadap Hasil Belajar Ditinjau dari Motivasi Belajar PLC di SMK. https://journal.uny.ac.id/index.php/jpv/arti cle/view/1600. Diunduh 4 September 2019. Diunduh tanggal 12 Januari 2020. 